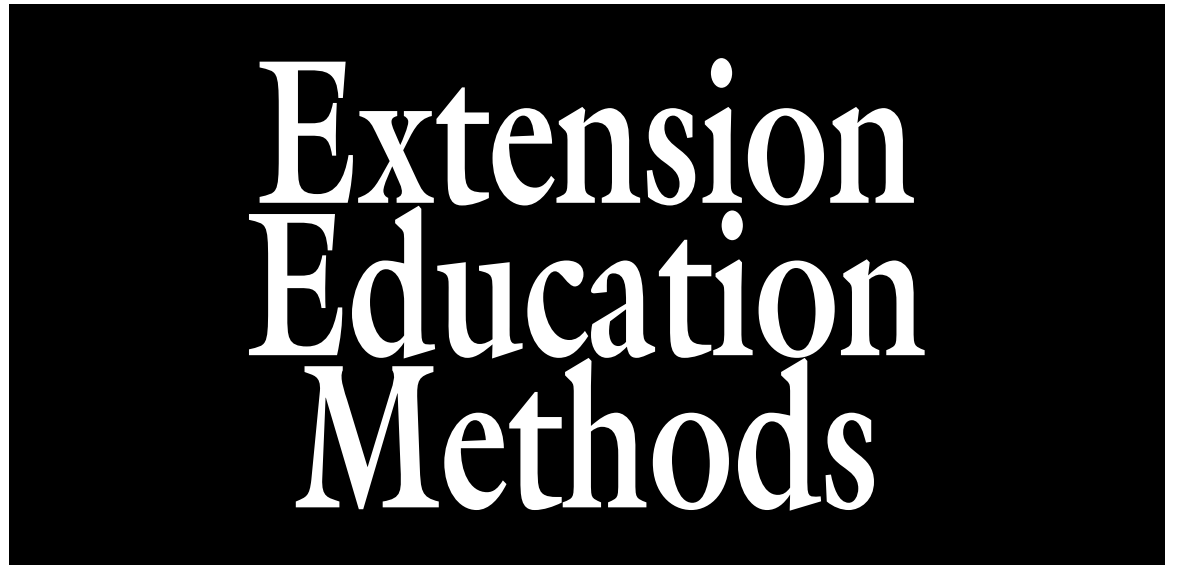

\title{
Summer Camp Garden Project: An Opportunity to Grow the Next Generation of Horticulturists
}

\author{
Carly Gillett ${ }^{1,4}$, Kathryn Fontenot ${ }^{2,5,8}$, Edward Bush ${ }^{3,6}$, \\ Maud Walsh ${ }^{3,7}$, and Charles Johnson ${ }^{3,7}$
}

\begin{abstract}
ADDITIONAL INDEX WORDS. agriculture careers, plant science, science education, state-mandated curriculum

Summary. Agriculture is fundamental to meeting Americans' basic needs-clothing, housing, and food. As the average farmer's age increases, there is a need to develop programs to encourage youth to pursue careers in agriculture and become the next generation of farmers. This study developed and implemented a horticultural curriculum focusing on vegetable production at a summer camp setting. Targeted participants were aged 9 to 12 years. Pre- and posttests were given to both the treatment group (campers participating in the victory garden track) and the control group (campers participating in a Wetlands track). The pre- and posttest evaluated campers' science-based knowledge and confidence. The study was replicated 16 times (weeks) over a 2-year study. Lesson topics included propagation, victory gardens, soil, recycling, plant parts, pollination, photosynthesis, and insects. Campers in the treatment group had improvement of general horticulture knowledge from pretest to posttest responses $18 \%$ improvement in 2010 and $11 \%$ improvement in 2011 . Posttest scores of treatment campers were greater $20 \%$ in 2010 and $16 \%$ greater in 2011 ( $P \leq 0.05)$ than control campers in both years of the study. Treatment campers were more confident $(P \leq 0.05)$ in explaining to others how to grow a plant and in their ability to grow more than one type of plant. Analysis of the 2 nd year of data-indicated treatment campers were more likely ( $P \leq$ 0.05 ) to feel confident in their ability to plant a seed that would later grow into a plant.
\end{abstract}

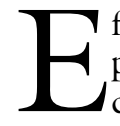
ffective agriculture education programs are essential in encouraging and preparing youth to pursue agriculture-based careers to maintain a continuity of local food and fiber production. The establishment of land grant universities by the Morrill Acts of 1862 and 1890 created a formal agriculture education system. Land grant universities provide access to higher education for the public and thus have the ability and responsibility to provide innovative agriculture practices to youth and potential future farmers. Informative kindergarten to 12th-grade science education can play an important role in this mission.

Several school garden studies indicate incorporating gardens into alternative curricula improved scores in specific areas such as science and literature (Karsh et al., 2009; Klemmer et al., 2005a; Pigg et al., 2006; Smith and Motsenbocker, 2005; Wagner and Fones, 1999). Other garden programs were created to engage student's interests and improve their science scores. Smith and Motsenbocker (2005) found integrating the Junior
Master Gardener Program into a fifth grade traditional science classroom increased student science knowledge. Klemmer et al. (2005a) demonstrated that additional science instruction provided to elementary students using garden activities, increased participants' scores on science achievement tests as compared with students receiving only conventional classroom instruction. Gardening programs positively affect students' knowledge and their environmental attitudes (Dirks and Orvis, 2005; Kahtz, 1995; Lohr et al., 2005; Midden and Stoelzle, 2000; Skelly and Zajicek, 1998; Taniguchi and Akamatsu, 2011). Karsh et al. (2009) presented garden and environmental lessons to middle school students and found participants in the garden curricula had higher scores in both scientific knowledge and environmental awareness. Of the studies mentioned, Karsh et al. (2009) and Smith and Motsenbocker (2005) both used pre- and postevaluations to determine gain in participant knowledge. However, not all garden-based programs resulted in significant improvement in either knowledge or environmental stewardship (Pigg et al., 2006; Kahtz, 1995).

The Louisiana State University Agriculture Center (LSU AgCenter) received funding from the U.S. Department of Defense and the U.S. Department of Agriculture to create a "victory garden" at a centrally located area of the state near several military bases, with intent to provide military and nonmilitary families a fun and educational outlet to learn about gardening. This experiment was designed to develop a gardenbased, hands-on curriculum to teach youth ages 9 to 12 years old basic gardening and environmental skills at a 4-H summer camp and to determine if the curriculum improved camper's science knowledge and confidence.

\section{Materials and methods}

Louisiana 4-H Summer Camp is composed of nine, weeklong sessions held each summer for youth ages 9 to 12 years old. Seven tracks were available to campers during their l-week camp experience. A track is a 9-h period of instruction divided into 3-h sessions hosted over three consecutive days. Available tracks included food and fitness, dramatic arts, science 
engineering and technology, wetlands, outdoor adventures, hunter safety, and the focus of this study, the victory garden track. On the first day of camp, campers chose one track to attend during the morning hours.

The victory garden area where the victory garden track was held included 18 raised beds $[4 \times 8 \mathrm{ft}(1.2 \times 2.4 \mathrm{~m})$ in dimension each] and an "in-ground" garden consisting of 10 rows, $4 \times 60 \mathrm{ft}$ $(1.2 \times 18.3 \mathrm{~m})$. A composting area provided space to actively engage campers in garden-based lessons and hands-on activities. Some of the raised beds were planted with vegetables before the start of camp, so campers would have harvestable produce during the camp as well as the opportunity to plant new vegetable transplants and seeds. Camp lessons were developed using Louisiana Grade Level Expectations (LaGLEs) (Louisiana Department of Education, 2016) for third through sixth grades; the LaGLEs are state mandated requirements each student must meet before passing to the next grade. The LaGLEs were reviewed to identify knowledge campers should possess as well new concepts that could be introduced through the gardening lessons. Lessons for this camp were developed by one of the coauthors, C. Gillett as part of her MS program. Lesson topics included core horticulture principles: propagation, victory garden, soils, composting, botany, pollination, photosynthesis, and garden pests. Each lesson topic addressed at least one LaGLE. The activities were hands-on to maintain student interest and to make the activities enjoyable, as this was a

\footnotetext{
This project was funded by a grant titled "Miss Lou: Connecting Kids and Communities," awarded by The U.S. Department of Defense and the U.S. Department of Agriculture.

${ }^{1}$ Louisiana State University, 10665 Farview Avenue, Saint Ann, MO 63074

${ }^{2}$ School of Plant, Environmental, and Soil Sciences, Louisiana State University Agriculture Center (LSU AgCenter), 155 JC Miller, Baton Rouge, LA 70803

${ }^{3}$ School of Plant, Environmental, and Soil Sciences, LSU AgCenter, 137 JC Miller, Baton Rouge, LA 70803

${ }^{4}$ Graduate Student

${ }^{5}$ Assistant Professor

${ }^{6}$ Associate Professor

${ }^{7}$ Professor

${ }^{8}$ Corresponding author. E-mail: kkfontenot@agcenter. lsu.edu.
}

doi: 10.21273/HORTTECH03572-16 summer camp setting. A few changes were made to the lessons in the 2 nd year. Campers were offered a more hands-on approach to the propagation, victory garden, and recycling/ composting lessons. In the propagation lesson, campers made a "garden buddy" by planting perennial ryegrass (Lolium sp.) seed in a knee high stocking decorated as a face in addition to planting vegetable seeds into a tray, as completed in year 1 of the study. In 2011 , campers were shown vintage victory garden posters created for war efforts and were asked to create their own advertising poster. This activity helped reinforce the importance of advertising victory gardens for the war efforts. In the recycling and compost lesson, campers not only worked with a large compost bin and were shown vermiculture bins. Each week, campers created a new bin using newspaper, soilless media, and worms from the existing bin. Worksheets were not used in 2011 for any of the lessons because campers felt written assignments were too similar to schoolwork. Lesson names, associated LaGLEs' lesson objectives, and test questions associated with each lesson are listed in Table 1. Full lesson plans are located in the appendix of C. Gillett's thesis (Gillett, 2012).

Treatment campers were those that participated in the garden track. The wetlands track campers were selected as the control campers because that particular track had high numbers of participants in all 16 weeks of camp over the 2 -year study. Both treatment and control campers completed a pre- and posthorticulture knowledge test and a confidence survey used to determine if the lessons improved campers' confidence in gardening. The horticulture knowledge test consisted of 16 multiple choice questions relating to the eight lessons presented in the victory garden Track. The confidence survey included four garden questions to assess how campers felt about their ability to garden. The confidence questions asked of the participants were 1) How sure are you that you can plant a seed that will grow into a small plant? 2) How sure are you that you can explain to your friends how to grow a plant? 3 ) How sure are you that you can grow more than one kind of plant? 4) How sure are you that you can grow a plant that produces a vegetable or food you can eat? Campers had three choices to choose from as an answer to the garden confidence question, "not sure at all," "somewhat sure," and "very sure." Campers in the victory garden track were given the prehorticulture knowledge test and confidence questions on Tuesday morning before lessons were presented and given the posthorticulture knowledge test and confidence questions after all lessons had been taught Thursday afternoon. Campers in the control group took tests Tuesday and Thursday after lunch during the time typically reserved for mail dispersal. Compensation for control campers included the privilege of eating first at the Thursday evening meal after they had completed both the pre- and posttests because camp attendance could be quite large, moving to the front of the line was a very enticing reward for control campers.

The exact same eight lessons were taught in 2010-11 with minor modifications in 2011 mentioned above. The confidence questions were not modified in 2011. In Summer 2010, 114 control campers and 120 treatment campers participated in this project. In Summer 2011, 114 control campers and 108 treatment campers participated in this project.

The horticulture general knowledge test data were statistically analyzed with PROC GLIMMIX of SAS (version 9.3; SAS Institute, Cary, $\mathrm{NC})$ and data were taken from differences of least square means test with a Bonferroni correction. Confidence question data were reported by converting data into a binary system. An answer of "not sure at all" received a numerical value of one, "somewhat sure" received a numerical value of two and "very sure" received a numerical value of three. For each student, the numbers corresponding to their given answers were added together for the four questions on the pre- and again on the postconfidence question survey. Responses from the preconfidence questions were subtracted from the postconfidence questions for each participant. If the participant gained confidence from the pre- to the postconfidence question survey, a positive difference, the results were represented as a one. If the participant did not change their response or lost confidence from pre- to postconfidence survey, the difference was represented as a zero. If the difference 


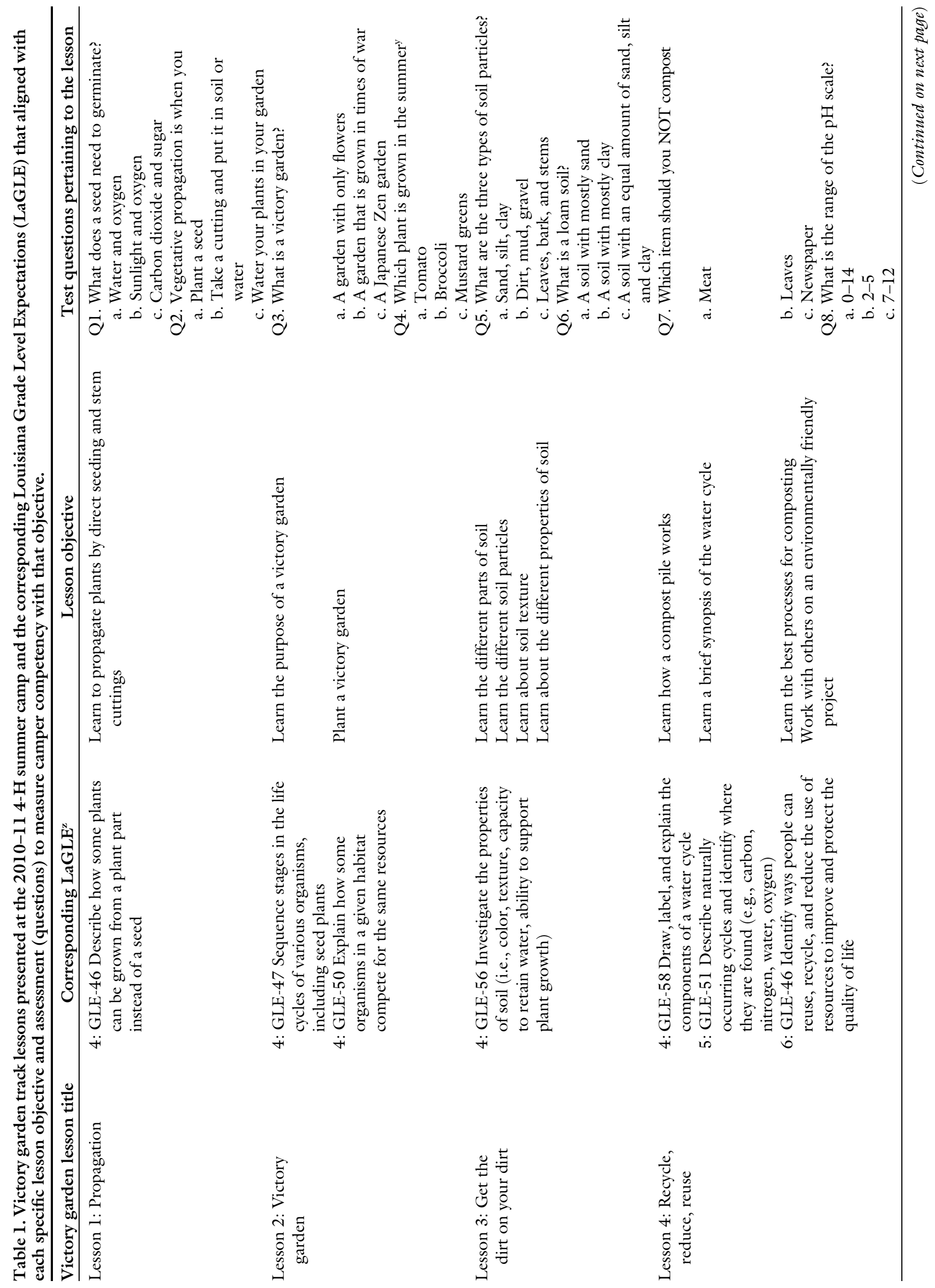




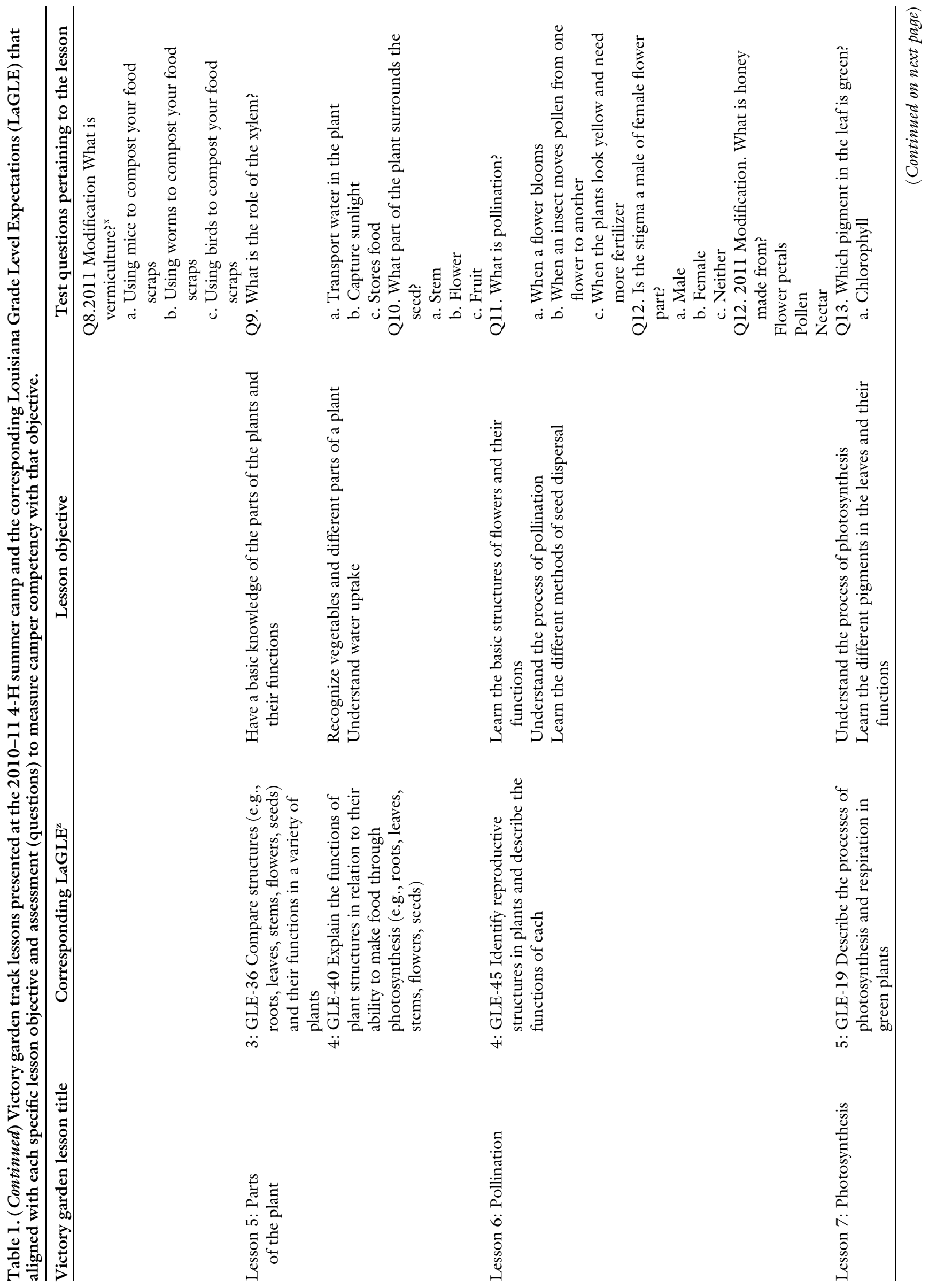

Hortlechnology · February 2017 27(1) 


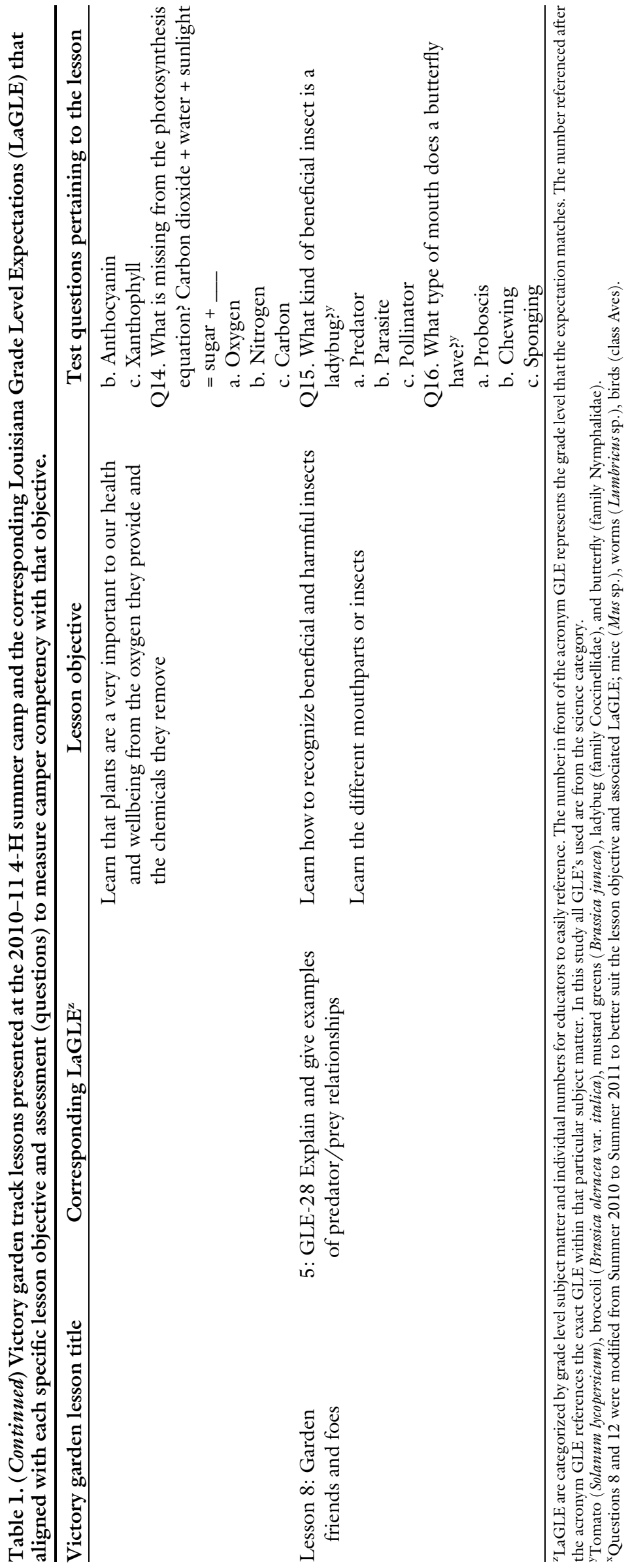

represented a negative value, the average confidence was less on the post- than on the preconfidence survey. For example, if a camper answered "not sure at all" on all four questions on the preconfidence survey his or her score was four. If that same camper answered "very sure" for all four questions on the postconfidence survey his or her total score was a 12. For this student, the gain was eight points therefore this result was entered as a one. Data were analyzed using a logistic procedure PROC LOGIT and data were taken from the Odds Ratio Estimate Table (SAS version 9.3; SAS Institute, Cary, NC). The model for the data $(\mathrm{Ql}$ Post $=$ Treatment Q1 Pre $)$ tested the effect the treatment or control had on the response. Because this study used living humans as subjects, approval from the LSU AgCenter Institutional Review Board (IRB) was sought. This project was officially exempted and given an IRB number HE-10-9 on 15 July 2010.

\section{Results and discussion}

PRE- AND POSTGENERAL KNOWLEDGE TEST RESULTS. In both summers of the study (2010-11) treatment and control campers scored similar results on the prehorticulture knowledge test (Table 2) indicating no difference in knowledge levels between the two groups at the beginning of each week of camp. Differences were noted between preand the posthorticulture test results within the treatment camper group both summers. Treatment campers improved scores between the preand posthorticulture knowledge test by $18 \%$ points in Summer 2010 and $11 \%$ points in Summer 2011 . Control campers did not improve test scores between the pre- and posthorticulture knowledge tests in either Summer 2010 or 2011 . Treatment campers in both Summer 2010 and 2011 scored higher on the posthorticulture knowledge test as compared with the control campers (Table 2). Our results are very similar to Smith and Motsenbocker (2005) where control and treatment students participated in a pre- and postevaluations to access potential knowledge change because of participation in a garden program. Smith and Motsenbocker (2005) showed that students participating in garden curriculum increased their 
knowledge from pre- to posttest but control students did not. These results were very similar to ours. Campers that participated in the summer garden track increased their science and garden knowledge on the posttest but control campers did not. This reinforces the idea that gardening is a valid method to teach science concepts in a fun and hands-on manner. Both our study, and Smith and Motsenbocker were seeking methods to improve science knowledge of elementary students, third to fifth grade in Smith and Motsenbocker and fourth to sixth grade in this paper. Additionally, Karsh et al. (2009) provided control and treatment middle school aged students with a pre- and postevaluation to determine if participation in horticulture-based curriculum improved science knowledge. Both years of the study, students participating in the additional horticulture lessons had higher posttest scores compared with pretest scores and participating students had higher scores on the posttest compared with the students not receiving additional horticulture lessons. Karsh et al. (2009) conducted horticulture lessons over 2 years as was done in this study. Participating students performed much better in year 2 as compared with year 1 (Karsh et al., 2009). The authors conclude that modifications to lessons and the instructor feeling more confident teaching in the 2 nd year possibly explain why the scores were different in the 2 years of the study. These results are similar to our program where average scores on pre- and posttests were different in the 2 years of the study. Like Karsh et al., we made changes to the lessons for the 2nd year and the instructor had more confidence teaching the activities. However, our study did not show the drastic improvement that Karsh et al. did. In fact, our study indicated that cores were better in the first year. The two papers show that when studying humans, many factors play into final test scores.

Confidence Question SURVey. During the Summer 2010 camp, confidence was gained by the treatment campers in explaining to a friend how to grow a plant and confidence in growing more than one type of plant (Table 3). In Summer 2011, treatment campers gained confidence for question 1 that addressed confidence in planting a seed that will mature into a small plant (Table 3 ). Camper confidence was not gained in growing a plant that produces a vegetable or food in either Summer 2010 or 2011. The control campers did not gain any gardening confidence. Confidence or how one "feels" is difficult to measure. Karsh et al. (2009) also conducted pre- and postevaluations to measure environmental attitudes or students' thoughts or feelings about the environment. Karsh et al. (2009) used the children's attitude toward the environment scale to measure attitudes and found differences in answers in each year of the study. In the Karsh et al. study, the students only improved attitude in year 2 . In our study, campers gained confidence in varying aspects in each year of the study but not more in

Table 2. Mean test scores on the pre- and postgeneral horticulture knowledge test given to control campers (who did not participate in the garden track) and treatment campers (who attended the garden track) at the 2010-11 Louisiana State University Agricultural Center's 4-H summer camp; Summer 2010 treatment camper $(\mathrm{N}=120)$, control camper $(\mathrm{N}=114)$; Summer 2011 treatment camper $(\mathrm{N}=108)$, control camper $(\mathrm{N}=114)$.

\begin{tabular}{|c|c|c|c|c|c|c|}
\hline Camper group & $\begin{array}{c}\text { Pretest } \\
\text { means score }(\%)\end{array}$ & $\begin{array}{l}\text { Posttest mean } \\
\text { score }(\%)\end{array}$ & $\begin{array}{l}\text { Difference } \\
\text { from pre- to } \\
\text { posttest }^{\mathrm{z}}\end{array}$ & $\begin{array}{l}\text { Pretest means } \\
\text { score }(\%)\end{array}$ & $\begin{array}{l}\text { Posttest mean } \\
\text { score }(\%)\end{array}$ & $\begin{array}{l}\text { Difference } \\
\text { from pre- to } \\
\text { posttest }^{\mathrm{z}}\end{array}$ \\
\hline$\underline{Y r}$ & & 2010 & & & 2011 & \\
\hline Treatment camper score ${ }^{y}$ & 52 & 70 & $* * *$ & 56 & 67 & $* * *$ \\
\hline Control camper score ${ }^{y}$ & 51 & 50 & NS & 53 & 51 & NS \\
\hline Difference on tests between & NS & $* * *$ & & NS & $* * *$ & \\
\hline
\end{tabular}

treatment and control campers ${ }^{\mathrm{y}}$

\footnotetext{
${ }_{{ }^{N} \text { S }}{ }^{* \star \star}$ Nonsignificant or significant at $P \leq 0.0005$ within columns. This represents the difference in scores between control and treatment campers. The horticulture general knowledge test data were statistically analyzed with PROC GLIMMIX of SAS (version 9.3; SAS Institute, Cary, NC) and data were taken from differences of least square means test with a Bonferroni correction.

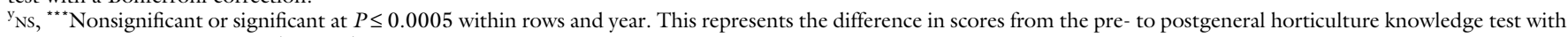
camper group's treatment and control.

Table 3. Scores on the confidence survey given at the 2010-11 Louisiana State University Agriculture Center's 4-H summer camp to control (nongarden track participants) and treatment campers (participants in the garden lessons and track); 2010 treatment camper $(\mathrm{N}=120)$, control camper $(\mathrm{N}=114) ; 2011$ treatment camper $(\mathrm{N}=108)$, control camper $(\mathrm{N}=114){ }^{\mathrm{z}}$

\begin{tabular}{|c|c|c|c|c|c|c|c|c|}
\hline & $Q^{1}{ }^{y}$ & Q2 & Q3 & Q4 & Q1 & Q2 & Q3 & Q4 \\
\hline & \multicolumn{4}{|c|}{2010} & \multicolumn{4}{|c|}{2011} \\
\hline Treatment camper & 0.1688 & 0.1039 & 0.1429 & 0.0519 & 0.2419 & 0.2016 & 0.0927 & 0.0887 \\
\hline Estimated difference & 0.52 & 0.32 & 0.18 & 0.45 & 0.38 & 0.74 & 0.76 & 0.79 \\
\hline Significance & NS & * & ** & NS & * & NS & NS & NS \\
\hline
\end{tabular}

"Answers for each question ( 1 = "not sure at all," 2 = "somewhat sure," 3 = "very sure") and camper were added together. The preanswers were subtracted from the postanswers. An increase in confidence in indicated by a positive number, a decrease in confidence is indicated by a negative number and no change is indicated by a value of zero.

${ }^{\mathrm{y}}$ Question $\mathrm{l}(\mathrm{Q} \mathrm{l})=$ How sure are you that you can plant a seed that will grow into a small plant? Q2 = How sure are you that you can explain to your friends how to grow a plant? Q3 = How sure are you that you can grow more than one kind of plant? Q4 = How sure are you that you can grow a plant that produces a vegetable or food you can eat? ${ }^{{ }^{N} \mathrm{NS},}{ }^{*},{ }^{*}$ Nonsignificant or significant at $P \leq 0.05$ or 0.005 , respectively. Data were analyzed using a logistic procedure PROC LOGIT and data were taken from the Odds Ratio Estimate Table (SAS version 9.3; SAS Institute, Cary, NC). 
l year than the other did. Discerning perceptions, attitudes, and confidence is extremely difficult. The creation of additional testing methods to assess student perception, confidence, and attitude of environmental or gardenbased programs would be extremely helpful to researchers.

\section{Conclusions}

Campers enrolled in the victory garden track at summer camp demonstrated knowledge gain in horticulture science $(P \leq 0.05)$, whereas control campers, enrolled in other themed camp tracks did not gain horticulture science knowledge. Participation in the victory garden track prepared campers for the coming school year by reinforcing and introducing fourth, fifth, and sixth grade science subject matter, as each of the victory garden track lessons aligned with specific LaGLEs. Treatment campers built their confidence in simple horticulture skills such as the ability to plant a seed that will grow into a small plant, the ability to explain to friends how to grow a plant, and the ability to grow more than one kind of plant. Our results align with Smith and Motsenbocker (2005), Kahtz (1995), and Karsh et al. (2009) who all determined that introducing science-based information through gardening lessons and activities reinforces and teaches students and in this case summer campers' basic science knowledge. These papers all indicate through pre- and posttest evaluation that students' science knowledge improves when participating in horticulture or garden activities. The results of this study suggest incorporating hands-on horticulture activities into existing camp settings would increase campers' science content knowledge and increase campers confidence in gardening skills. Incorporation of horticultural activities into camp was a small step toward helping youth consider engaging in higher agricultural education or working in an agricultural-based career.

\section{Literature cited}

Dirks, A.E. and K. Orvis. 2005. An evaluation of the Junior Master Gardener program in third grade classrooms. HortTechnology 15:443-447.

Gillett, C. 2012. Creating a horticultural curriculum addressing environmental concerns. MS Thesis, Louisiana State Univ., Baton Rouge. 6 Dec. 2016. <http://etd. lsu.edu/docs/available/etd-04192012115227 /unrestricted/gillett_thesis.pdfs.

Kahtz, A.W. 1995. Impact of environmental education classes at the Missouri Botanical Garden on attitude and knowledge change of elementary school children. HortTechnology 5:338-340.

Karsh, K., E. Bush, J. Hinson, and P. Blanchard. 2009. Integrating horticulture biology and environmental coastal issues into the middle school science curriculum. HortTechnology 19:813-817.

Klemmer, C.D., T.M. Waliczek, and J.M. Zajicek. 2005a. Growing minds: The effect of a school gardening program on the science achievement of elementary students. HortTechnology 15:448-452.
Lohr, V., I. Caroline, and H. PearsonMims. 2005. Children's active and passive interactions with plants influence their attitudes and actions toward trees and gardening as adults. HortTechnology $15: 472-476$.

Louisiana Department of Education. 2016. Academic standards and grade level expectations. 23 Sept. 2016. <https:// www.louisianabelieves.com/resources/ library/academicstandards $>$.

Midden, K. and J.C. Stoelzle. 2000. An evaluation of a children's garden in developing a greater sensitivity of the environment in preschool children. Hort Technology 10:385-390.

Pigg, A.E., T.M. Waliczek, and J.M. Zajicek. 2006. Effects of a gardening program on the academic progress of third, fourth, and fifth grade math and science students. HortTechnology 16:262-264.

Skelly, S.M. and J.M. Zajicek. 1998. The effect of school gardens on children's interpersonal relationships and attitudes toward school. HortTechnology 8:579-583.

Smith, L.L. and C.E. Motsenbocker. 2005. Impact of hands-on science through school gardening in Louisiana public elementary schools. Hort Technology 15:439-443.

Taniguchi, T. and R. Akamatsu. 2011. The relationship between farming experiences and attitudes toward locally grown foods among Japanese children. HortTechnology 21:355-358.

Wagner, L.K. and S.W. Fones. 1999. Enhancing science education experiences through garden explorations: An inquirybased learning opportunity at the South Carolina Botanical Garden. Hort Technology 9:566-569. 